\title{
A review of technical solutions for RCCI engines
}

ARTICLE INFO

Received: 15 July 2021

Revised: 23 September 2021

Accepted: 23 September 2021

Available online: 25 September 2021
Engines working in dual-fuel mode need special conditions to ignite air-fuel mixture without spark plug in a good moment with high combustion efficiency. To create homogenous air-fuel mixture the conditions in the cylinder are even more demanding. Many concepts of ignition was developed, but the most effective needs perfect mixing of fuel and air, which is a serious technical challenge. Technical solutions for dual-fuel engines cover the complexity of these problems thus leading to the further development of ignition systems in internal combustion engines. Fuel supply systems, the operation strategy of them, the shape of the combustion chamber are the most important elements to change and develop for correct operation of dual-fuel engines. The literature analysis showed a small amount of research carried out to optimize the operation of dual-fuel engines The variety of engines in which a dual-fuel system can be used requires much more research about them, and solutions necessary for their correctly operation.

Key words: HCCI, RCCI, Dual-Fuel, DDFS

This is an open access article under the CC BY license (http://creativecommons.org/licenses/BY/4.0/)

\section{Introduction}

Internal combustion engine (IC) and the combustion process itself are constantly developing from XIX century until today. The amount of energy released in the combustion chamber and the composition of raw exhaust gases both depends of combustion. The improvement of these processes in first century of IC engines existence was mainly based by improving the shape of combustion chamber. The next century opened an opportunity for researchers to develop new solutions of the air-fuel ignition methods. These fresh solutions introduced new directions in the development of internal combustion engines.

\subsection{Explication}

IC engines always emit undesirable exhaust components, even if they are the most efficient, modern and equipped with, even the best exhaust gas cleaning systems. Usually systems of this type may be large and complex [9]. The typical composition of exhaust gases from marine engines are shown on Fig. 1.

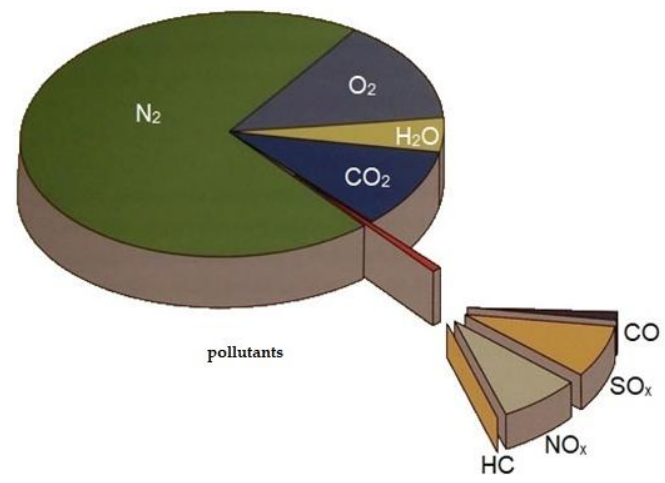

Fig. 1. The typical composition of exhaust gases from the modern, marine diesel engine (reproduced from [9])

Composition of exhaust gases is strongly dependent on what kind of fuels are used in the engine. In order to be able to use many types of fuels while maintaining a modern and well-developed combustion technology, engines have been modernized, allowing for the combustion of many fuels at the same time. This type of solution is Dual-Fuel (DF) system. DF may turn out in the future as a key point in the development of IC engines and reducing the emission of harmful exhaust components.

This work was created in order to distinguish specific solutions enabling the implementation of the most effective DF combustion systems in classic piston CI engines. A lot of works focusing on the literature review have already been done. The researchers selected engines used in various research studies, with a method of air-fuel mixture combustion similar to that one was focused for this study [22]. A very detailed review of carried out tests in analyzed studies engines performance are presented in detailed tables and summarized in the description without going into the deep technical details regarding the design of the engine and the technical solutions used in them. More detailed data on technical solutions are presented in the different studies [24, $25]$. Authors decided to refine and expand with additional information from further literature analysis. Works such as [29] and [23] present a detailed description of the research carried out, and the influence of various types of fuels on engine performance, that which are not main focus in this study. The above-mentioned works also take into account the simulation results, which in this paper is limited to presenting the concept of technical solutions that may bring beneficial effects. Model simulations for the marine engine presented in the study [23] are a very important part of research on this topic due to the advantages that slow- and medium-speed engines working in the DF mode have. This study is also largely based on technical solutions used in marine engines, the development of which largely determines the future of DF engines, which is supported by many publications [18-20,34], including technical solutions in marine engines.

The studies quoted here may constitute the core of considerations, developed with technical issues enabling the 
implementation of engine operation in DF systems. Important issue which is also highlighted in this article is the flow of technology from large industrial engines to small drive units. The technical solutions presented in this work show the current state of technology and define the possibilities that arise from their widespread use and the combination of independently used technical solutions.

\section{IC engines ignition systems}

A simplified view of engine development through the centuries of existence of IC engines reflects the mainstream of their development. Figure 2 shows the important types of air-fuel mixture ignition systems regarding to the date of their construction.

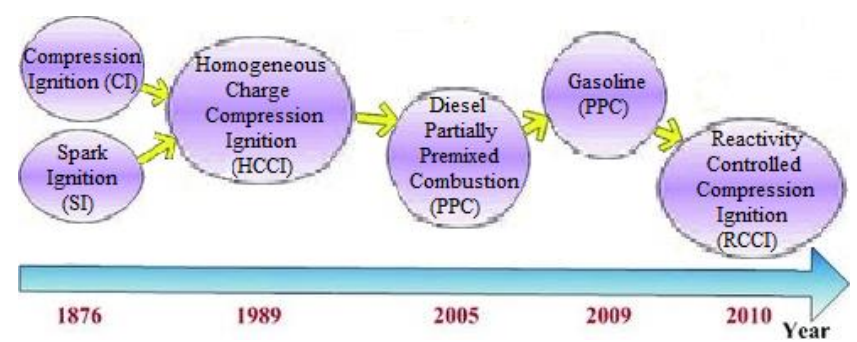

Fig. 2. Chosen ignition methods in ICE by year of construction (own graphic based on data and graphics from [25])

Ignition systems in IC engines are being developed one dependent on the other and the new design is replacing the old one. Relations between different ignition systems allow for further exploration of various IC engines concepts. Different ignition types are shown on the graph showing addiction of their use on fuel type (Fig. 3).

\begin{tabular}{|c|c|c|c|c|c|c|}
\hline \multicolumn{2}{|c|}{ Low-Prevents Auto-Ignition } & \multicolumn{3}{|c|}{ Fuel Reactivity } & \multicolumn{2}{|c|}{ High $=$ Promotes Auto-Ignition } \\
\hline $\begin{array}{l}\text { Stoich } \\
\text { GDI }\end{array}$ & $\begin{array}{l}\text { Lean } \\
\text { GDI }\end{array}$ & $\begin{array}{l}\text { Gasoline } \\
\mathrm{HCCl}\end{array}$ & PPC & $\begin{array}{l}\mathrm{RCCl} \\
\mathrm{DF}\end{array}$ & $\begin{array}{l}\text { Diesel } \\
\mathrm{HCCl}\end{array}$ & $\mathrm{PCCl}$ \\
\hline
\end{tabular}

Fig. 3. The dependence of the methods of ignition of the air-fuel mixture in IC piston engines on the method of fueling the engine and the type of fuel used (own graphic based on data and graphics from [25])

Different engine ignition types are designed for use with certain fuels. The combination of some solutions may result in a significant increase in the efficiency of IC engines. Their development is possible only thanks to research on single types of ignition. DF technology is now paramount in further improving engine combustion.

\subsection{IC engines ignition systems}

The typical way of using fuels in IC engines is based on the use of one type of fuel that ignites either as a result of forced spark ignition (SI) or as a result of compression ignition (CI). It allows for better use of the chemical energy contained in the fuel due to the higher efficiency of this type of engines. However, the highest efficiency is currently achieved thanks to the ignition of a homogeneous air-fuel mixture, which can be ignite by spark or by compression. In Homogeneous Charge Compression Ignition (HCCI) the ignition of all the fuel in the combustion chamber occurs simultaneously. This combustion takes place at a lower temperature than in a classic diesel engine, which leads to lower heat losses and the less $\mathrm{NO}_{\mathrm{x}}$ formation. It translates

into higher thermal efficiency of engines with this type of ignition. However, in order to achieve ignition in the combustion chamber of the engine, very specific conditions are required, which are difficult to achieve [5]. Effective control of the moment at which ignition takes place in all areas of the engine operation is currently beyond the possibilities of designers. Fuel used in that type of engine must have a high octane ratio, because of its early injection. For this reason, one of the variants of engines with this type of ignition method, which has the full potential of use today, is an engine powered by two fuels by Reactivity Controlled Compression Ignition (RCCI).

RCCI is an ignition method in which high reactive fuel such as diesel fuel injected directly into the cylinder mixing with the air and self-ignites a of low reactive fuel, which is delivered to the combustion chamber earlier via indirect injection. The same way of fueling the engine characterizes a classic dual-fuel engine in which the fuel-air mixture is not homogeneous. Every modern dual-fuel engine is currently developed in the direction that allows the formation of a homogeneous air-fuel mixture [32]. Schematic of classic dual-fuel injection system is shown on Fig. 4.

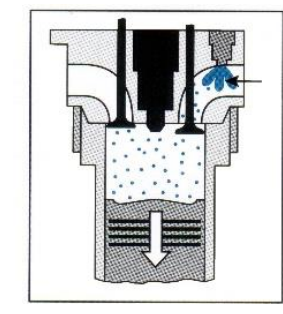

Fig. 4. Schematic drawing of direct dual-fuel injection engine work (reproduced from [9])

Before RCCI, there was a few conception which could generate better IC engines parameters. When the first engines in which a homogeneous fuel-air mixture was burned were developed, partially pre-mixed combustion (PCI) and partially premixed compression ignition (PPCI) was known. This type of ignition allows a mixture that has already been pre-mixed with air to be burned. Only when the last dose of fuel is injected into the cylinder, a fuel-air mixture is formed. In contrast to PCCI or HCCI, the name emphasizes that only a part of the fuel was mixed with air before ignition. Thanks to this method of fuel combustion, a large part of it is burned earlier than in conventional CI [12]. Gasoline Direct-injection Compression Ignition (GDCI) engine is operating basically on the same principle as PPCI or even PCCI. Difference is that the fuel used in this case is gasoline. The operation of such an engine is difficult to maintain, but since 2010 the concept of such an engine has been constantly developed [15]. HCCI ignition not possible at the current level of knowledge for use in the entire range of operation in modern piston engines. This is the basic difficulty with the widespread introduction of this type of ignition in IC engines, and it consists a number of technical problems still unsolved. Considering that these problems must be faced by HCCI and PCCI engine designers, a new concept has been introduced for a specific type of ignition: Spark (Plug) Controlled Compression Ignition (SPCCI) or Spark Assist Compression Ignition (SACI). It is self- 
ignition controlled by spark plug. It is a specific method of self-ignition of a homogeneous air-fuel mixture located in the combustion chamber [30]. This type of ignition is currently in use, but mastering the ignition of a homogeneous air-fuel mixture without spark plug assist is now possible only in RCCI engines, and these kinds of ignition are the keys to introduce diesel HCCI or PCCI engine.

\subsection{Dual-Fuel ignition systems}

RCCI is a special type of HCCI engine that allows to use many types of fuels with high combustion efficiency and low emission of harmful exhaust components.

The low-temperature method of burning fuels in HCCI engines allows to improve the efficiency of the engine, thanks to the reduction of energy lost during combustion process. For the further development of auto-ignition engines, with increasing the range of fuels used in it, it is necessary to control the air-fuel mixture auto-ignition by using the injection of second fuel injected into the combustion chamber. The development of modern compression ignition engines is strongly dependent on engines with this type of ignition. Using two fuels with different physicochemical properties makes it possible to control the time of compression ignition and allows to use engine in full range of operation [2].

The engine working in dual-fuel mode with diesel fuel as the reactive fuel requires only the already mentioned, pilot dose of diesel fuel to initiate the ignition. The Fig. 5 below shows a schematic view of the power supply and ignition in an RCCI engine powered by a mixture of gas fuel as the low reactive fuel and diesel as the high reactive fuel [29].

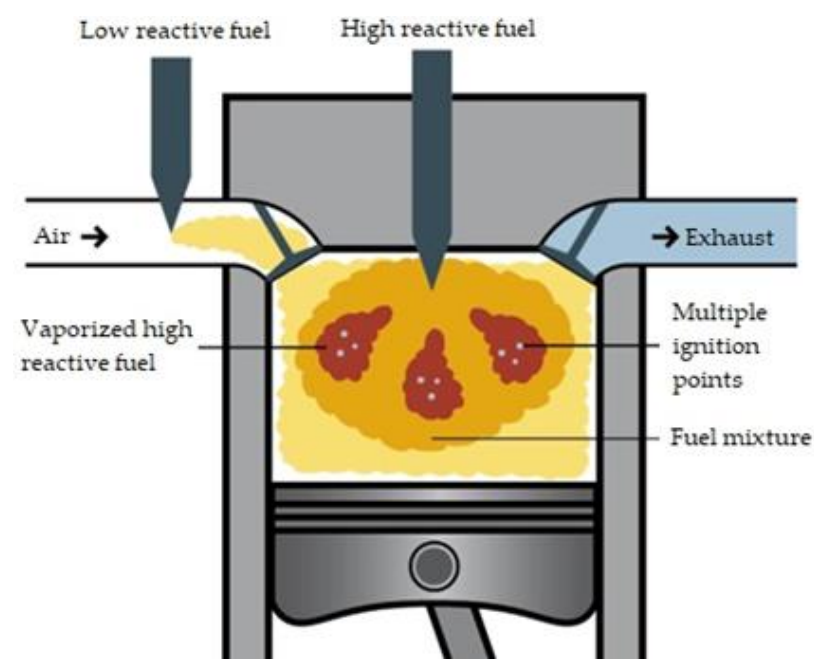

Fig. 5. Ignition and combustion in the RCCI engine (custom artwork based on [37])

In RCCI engines, low-reactive fuel, with a high octane number, is supplied to the engine along with the air through the engine's intake system. Low-reactive fuel is compressed and mixed with air to form of pre-mixed, combustible fuelair mixture. It can be classic gasoline, alcohol, LPG, CNG or any liquid fuel with high octane ratio. Due to the high resistance to auto-ignition and knocking combustion, this mixture will not ignite despite the high temperature and pressure already in the cylinder. In the vicinity of TDC, high reactive fuel (diesel, bio-oil, GTL, CTL or HVO) is injected. This kind of fuel must be characterized by good self-ignition properties, including a low ignition temperature and the ability to large atomization of the fuel in the process of its injection. Ignition of high-reactive fuel initiates ignition of the air housing with low-reactive highoctane fuel. The essence of controlling the moment of ignition and the course of combustion of fuels used in the engine is the injection time and properties of the reactive fuel.

When using additional, low reactive fuel in DF CI engine, it's necessary to increase the amount of injected diesel fuel due to the insufficient resistance of the additional fuel to knocking combustion. Its occurrence depends on many factors, but mainly the type of fuel and the compression ratio in the engine. Knocking combustion causes the formation of uncontrolled foci of fuel self-ignition, which hinder the proper course of the combustion process and the operation of the IC engine. Its presence determines the possibility of using fuel in the engine and the degree of substitution of the basic fuel.

There is also a different fueling strategy in this type of fuel called Direct Dual Fuel Stratification (DDFS) - the difference is the use of direct injection for both fuels used in the engine [26]. Direct injection of two fuels requires the use of several injectors, or a special design injector, such as the offered product proposed by Westport corporation [34], and described in all relevant publications covering dual-fuel engine solutions [16]. Schematic show of direct dual-fuel injection work is shown on Fig. 6.
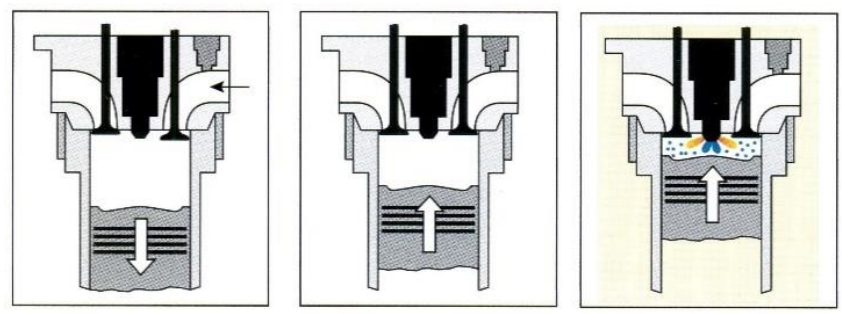

Fig. 6 Schematic drawing of direct dual-fuel injection engine work (reproduced from [9])

DDFS is a specific kind of RCCI engine, where both fuels are direct injected into the combustion chamber, where part of the low-reactive fuel is injected early enough to mix with the air, while the remaining part of the fuel can be injected in the piston's upper dead center - depending on the engine's needs [13].

There are many strategies for fueling RCCI engines and they are constantly being developed. Many solutions depend on fuels which are used in a particular RCCI engine. In the case of gaseous fuels used as low-reactive fuels, the basic parameter that is being attempted to maximize is the percentage of replacing diesel fuel with gaseous fuel. The value of this parameter strictly depends on the level of adaptation of a given engine to dual-fuel operation. Researchers want to achieve a high value of this parameter due to fuel prices and the level of emission of harmful exhaust components that can be achieved with the use of certain fuels. In most DF engines, the value of this parameter is not constant and it is not possible to maintain its high 
value under high engine load. Depending on the stratification and the degree of mixing of high-octane fuel with air, the course of its combustion can be characterized in various ways, and this is often a key issue in RCCI combustion studies. The amount of fuel of a given types depends to the greatest extent on the engine load and the fuel injecting system. Figure 7 shows the chart with the dependence of the engine powered by natural gas (NG) and diesel fuel on the possibility of using both fuels in different proportions.

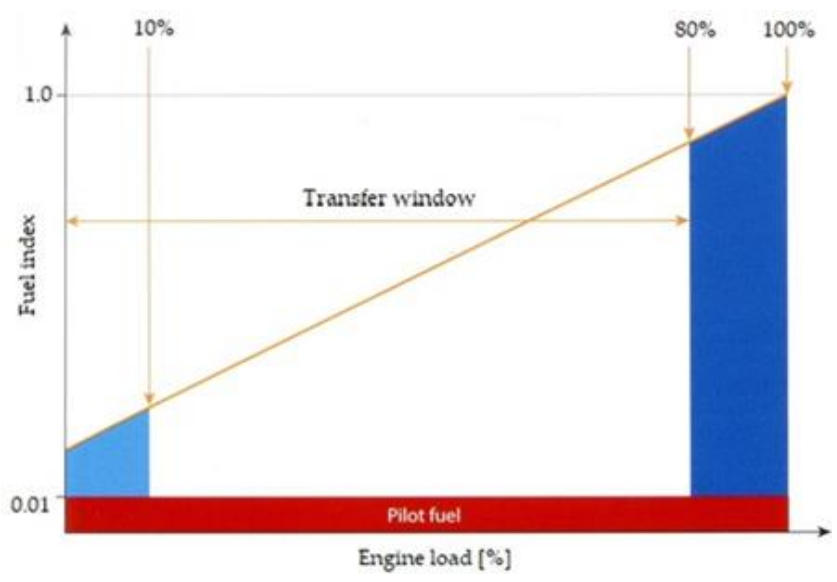

Fig. 7. The various operating conditions known as "modes" for dual-fuel engines, where horizontal is the engine load between $0-100 \%$, and vertical is the fuel-index from 0 to 1 or 0 to $100 \%$ (reproduced from [11])

Figure above shows the DF engine fueling strategy: where the red color is pilot-fuel injection active, light blue shows that engine can be started, operated and loaded in gas mode- here engine will trip to back-up fuel after a present time, if engine load is not increased out of this area, and dark blue color means that this engine is able to run up to $100 \%$ load on either fuel, but transfers from liquid to gas are not permitted above $80 \%$ load - transfers from gas to liquid are permitted at any load. As high the fuel index is, as much liquid fuel must be used [11].

Fuels used in engines significantly influence the shape of this type of graph. Essentially all liquid and gaseous fuels of relatively high or relatively low octane numbers can be used in RCCI engines. Only those fuels that cannot be clearly classified as highly reactive or low reactive fuels would be difficult to apply in RCCI engines. If it is possible to create a homogeneous mixture of low reactivity fuel with air, this fuel may also self-ignite under the influence of pressure exerted on it by a rapidly burning highly reactive fuel, and in those option engine can be called RCCI engine. If the self-ignition occurs without forming homogeneous air-fuel mixture, the engine can be called only a DF engine. From the fuels used in those type of engines alcohols that are bio-based fuels contain in their compounds may facilitate the formation of a homogeneous mixture in the combustion chamber, so sometimes it depends on the fuel used in a given engine.

Thanks to the use of a low-reactive fuel homogeneously mixed with air, the efficiency of using the chemical energy contained in the fuel increases. Its increase is also influenced by the even temperature distribution in the combustion chamber. This reduces the total amount of heat pene- trating the cylinder walls and prevents the formation of hot spots within the cylinder what is clearly visible in Fig. 8. The maximum combustion temperature in the combustion chamber is lower than in conventional compression ignition engines.

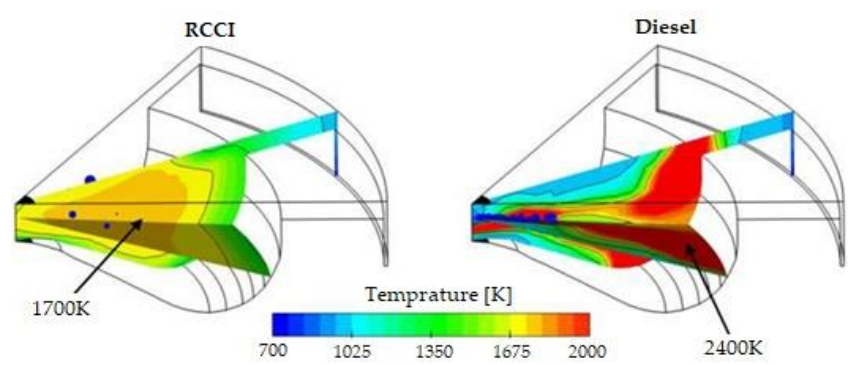

Fig. 8. Temperature distribution in the combustion chamber for a RCCI engine powered by $\mathrm{CNG}$ and diesel and a classic diesel engine powered only by diesel (modified graphic based on [7])

Due to the even and low-temperature course of the combustion process, the emission of nitrogen oxides, solid particles and soot is reduced, just like in the classic HCCI engine. High flame temperature is one of the main factors causing the formation of nitrogen oxides during the combustion process. Nitrogen oxides are not formed in RCCI engines as intensively as in a classic diesel engine. Due to the combustion close to the stoichiometric composition, the amount of oxygen and nitrogen in the combustion chamber during the process is therefore reduced compared to a classic diesel engine [36].

The real benefits of lowering the combustion temperature appear in large, low-speed marine engines, where the problem of cooling the combustion chamber is solved in more ambitious ways than in a small piston engines. Piston and combustion chamber cooling is more advanced, because it is possible in engines of such dimensions. Figure 9 shows the drilled holes in the large engine piston.

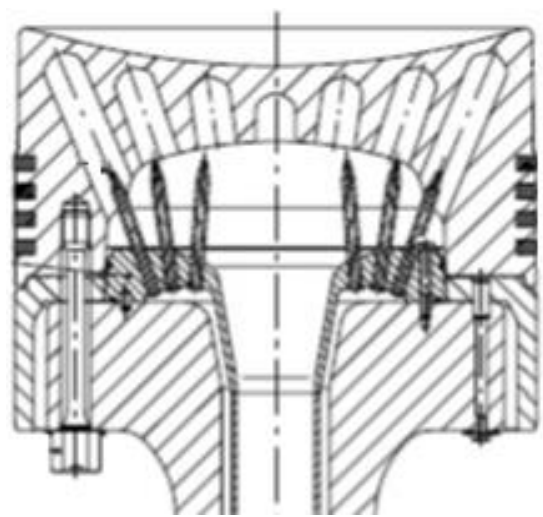

Fig. 9. Example of piston cooling drills in the Sulzer IC engine (reproduced from Pounder's Marine Diesel Engines [35] with permission from Elsevier)

Drills made in the piston enable its effective cooling with the use of engine oil. The differences in combustion temperature between conventional CI engine and HCCI or RCCI engine can potentially eliminate the need for such a solution. The lower temperature reduces the occurrence of the $\mathrm{NO}_{\mathrm{x}}$ formation effect, which obviously allows limiting 
the participation of SCR in changing the composition of exhaust gases. Low emissions that can be achieved in research engines requires significant interference in the design of the IC engine, preceded by its research and optimization of the design for the combustion of a new type of fuel. In both single-fuel diesel engines and dual-fuel diesel engines (RCCI), it is required to adapt the combustion chamber to run on a new type of fuel [7]. In the present CI engines the combustion chamber is widely profiled inside the piston. Fuel injection shape depends on to the combustion chamber shape too. Figure 10 shows the potential of injection angles for typical DI engine.

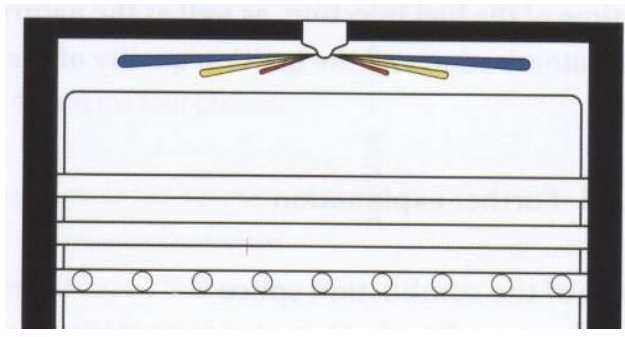

Fig. 10. Shown of the fuel injection process with various fuel-injection possibilities in example of different angles of injection (reproduced from [9])

This ability to inject fuel in different angles is greatly needed in RCCI engine. Some studies [4, 8, 29] has repeatedly shown that the shape of the combustion chamber in RCCI engines is very important for the formation of harmful chemical compounds contained in exhaust gases. Standard injection shapes in CI engines are showed in the Fig. 11. Those shapes and angles of injection in standard CI engines are not good enough for RCCI.

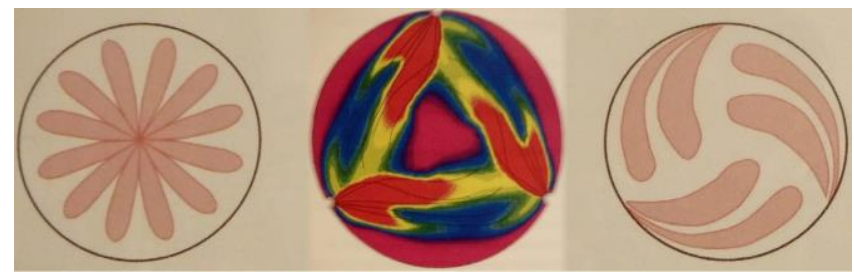

Fig. 11. Shown of the correct injection spray shapes in the injection flow of a four-stroke trunk-piston engine (left), in a large two-stroke crosshead engine with three injectors (centre), and a two-stroke crosshead engine (right) (reproduced from [9])

Those shapes and angles of injection in standard CI engines are not good enough for RCCI. While DF engines are often derived from standard CI diesel engine conversion, the limitations that result from this should be borne in mind. Defining the needs for RCCI engines reliance on such limitations, and on fact, that the most that the biggest changes involve the engine combustion chamber. Next chapter will focus on these shifts, where they can be divided into technical solutions including the construction of the piston combustion chamber and the fuel injector.

\subsection{Important RCCI technical solutions}

The basic technical modification that should be carried out on an existing engine adapted to work in RCCI mode is the change of its combustion chamber and modification of the power supply system.
Important in that point is that combustion chamber space that can enable proper work of the single fuel CI engine will have a swirl ratio of low reactivity fuel problems and can have a hot spots on its surface, what which disqualifies the possibility of using low reactive fuel with an octane number that does not provide resistance to spontaneous combustion in contact with such a hot point on the surface of the combustion chamber. When dealing with this problem, designers often use additional cooling of some elements (e.g. injectors), which heat up excessively in the combustion processes [28].

The shape of the RCCI combustion chambers, with different compression ratio options, compared to the combustion chamber of a modern CI engine is shown in the Fig. 12 .

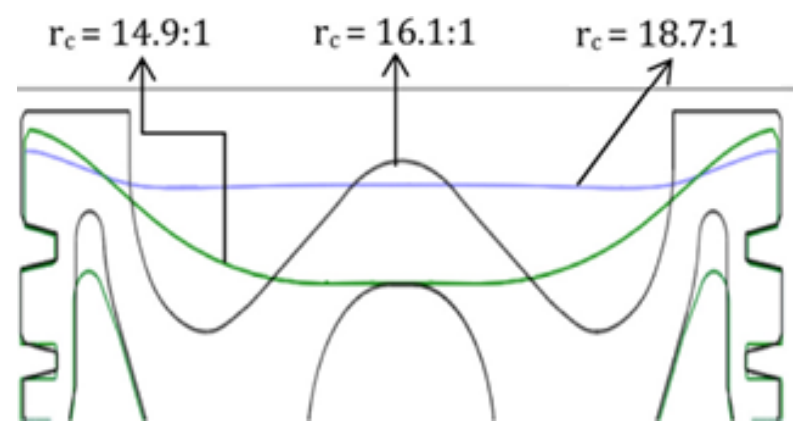

Fig. 12. Comparison of RCCI and classic CI engine piston with combustion chamber inside of it (reproduced from [31])

Form of combustion chamber in RCCI engine is fundamentally different than in classical CI diesel engine. The swirl ratio of air-fuel mixture must be higher, surface of combustion chamber can be much smaller, and the shape itself will be softer. In the Fig. 13 is shown the cross section of the piston where the sharpest edges of the combustion chamber are colored by the red circles.

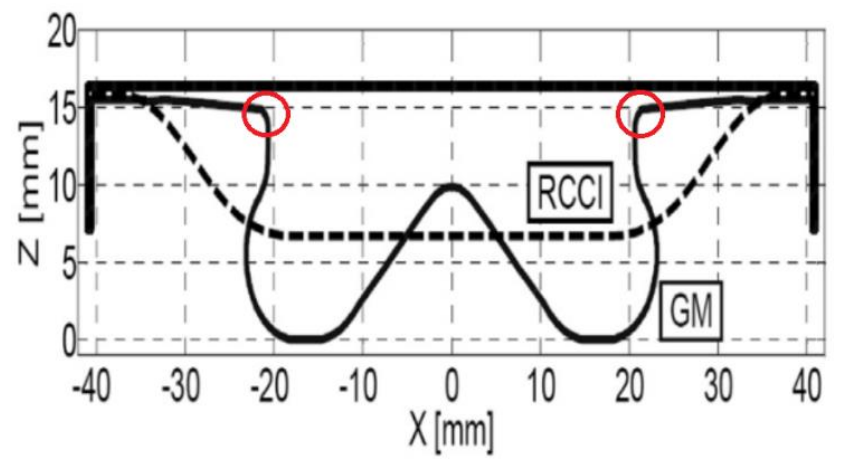

Fig. 13. Cross-section drawing of GM stock piston (solid line) and modified RCCI piston (dotted line) (reproduced from [6])

Injection of high reactivity fuel in RCCI engine takes place differently than in a classic diesel engine. Direct injection of high reactivity fuel with a centrally located injector in a classic CI engine requires the use of a combustion chamber located in the piston, the shape of which is optimal only for single-fuel engine operation. DF operation needs different combustion chamber shape. The amount of this fuel itself is many times lower in most of the engine operation area, so the space required for uniform mixing of the 
injected fuel is not so great, but the places where the fuel must be delivered are extended by the area above the piston and the combustion chamber hollowed in it. Because there is already low-reactive fuel in the entire in-cylinder space over the piston, high reactive fuel must be delivered to an area already filled with this fuel. It forces a change of the place where the fuel will be injected. The changes in the injector design alone will not be enough and the researchers decided to change the factory piston into custom piston. More important is the issue of correct swirling of the airfuel mixture $[4,8,29]$. These parameters have the greatest impact on the degree of swirling of the fuel-air mixture, which for different proportions of the fuel mixture has a different impact on the efficiency of their use. The red edges of the combustion chamber in the RCCI engine constitute a serious barrier to the proper distribution of the injected highly reactive fuel inside the combustion chamber. It is necessary in existing engines to modify them in order to improve the distribution and swirling of the air-fuel mixture. Researchers in [1] prepared project from the original GM piston to modify it into investigatory RCCI piston. Effects are shown in the Fig. 14.

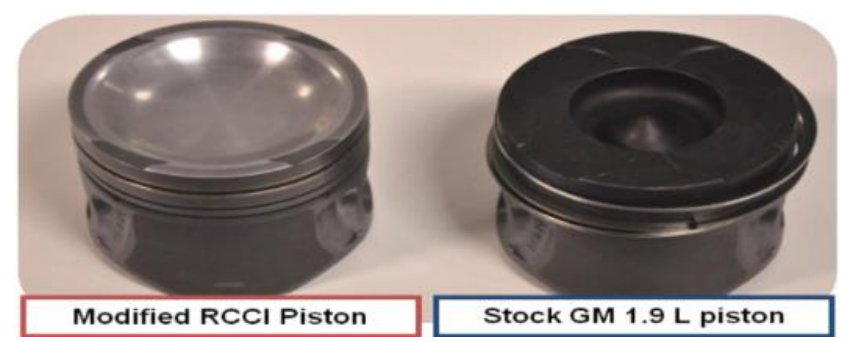

Fig. 14. Photo of modified RCCI piston and stock GM 1.9 L piston (reproduced from [1])

Project of RCCI piston has been meticulously prepared and, after its construction, installed and used for further research. Researchers indicate an increase in the thermal efficiency of the engine thanks to the use of such a piston. Such scientific efforts are very much needed because there is not enough research into RCCI engines to interfere with the essential design of existing engines. In the Fig. 15 plans comparison both pistons are shown.

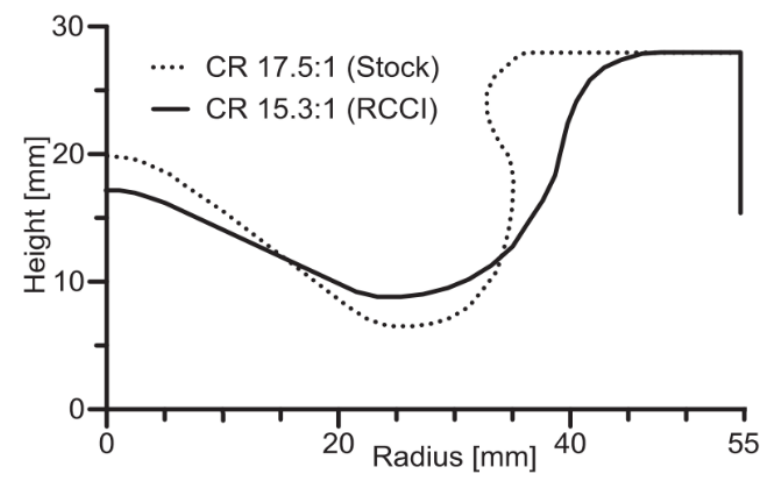

Fig. 15. Differences between piston bowl geometries in different compression ratios for RCCI engine, and classical diesel engine (reproduced from Applied Energy [22] with permission from Elsevier)

In order to adjust the combustion chamber in the piston for DF combustion, the researchers proposed an alternative shape of the combustion chamber [22], which is shown in comparative Fig. 16, containing two numerical models of combustion chambers.

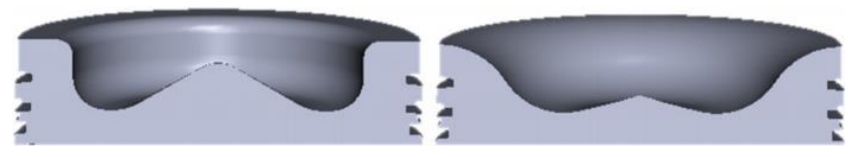

Fig. 16. Potential of piston combustion chamber geometries (reproduced from [22])

Conceptions of bowl piston geometry for RCCI engines are new and different. Most of them are computer simulations concepts, but researchers [1, 7] create real piston which was showed in the Fig. 14, and prepared technical documentation for different piston shapes for testing RCCI engines, showed in the Fig. 17.

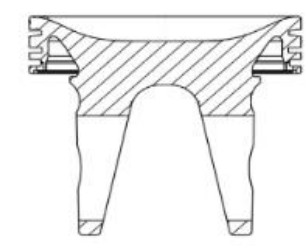

(a)

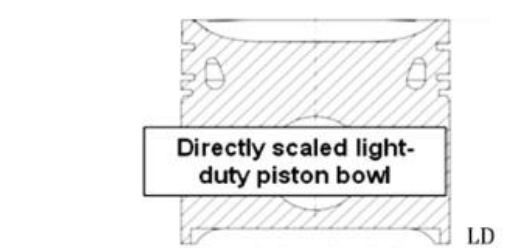

(b) piston with scaled HD bowl shape RCCI

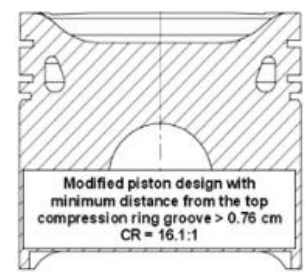

(c) piston final version LD RCCI

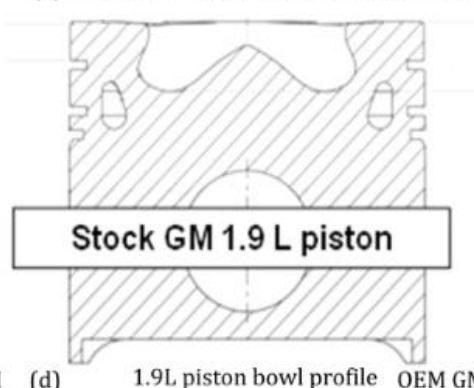

Fig. 17. Comparison of piston bowl geometries (graphic based on [6])

The geometry of RCCI piston is strongly dependent on the injector position and spray shade. There is multiple option for further research about it. The good example can be quoted in work where researchers focus on negative valve overlap (NVO) process as a promising variable valve actuation (VVA) measure to improve low-load efficiency in RCCI engines and (external) fuel reforming techniques to improve low temperature combustion (LTC) performance in those engines [19]. Was shown that low-load RCCI operation can be improved with a combination of NVO and direct diesel injection into recompressed residuals. Validating this hypothesis was the goal of their research in which they create computer simulation of the present research. In this work it's possible to find that even the fuel supply system effects on correct injection shape and piston bowl geometry what is showed in the Fig. 18.
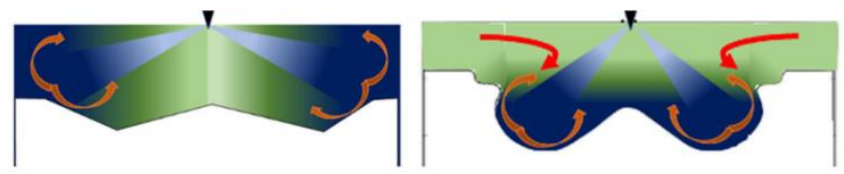

Fig. 18. Piston bowl geometries and injection configurations in a different fuel supply systems in RCCI engines (reproduced from Applied Energy [19] with permission from Elsevier) 
The way the fuel is supplied to the RCCI engine affects the geometry of the combustion chamber and the shape of injection of highly reactive fuel. On the left part on Fig. 18 the Single Point Injection (SPI) with mixer after turbocharger is showed, and on the right site is Port Fuel Injection (PFI) to individual cylinder ports. It is important to say at this stage that the generally specified methods of supplying the engine can be correlated with other engine supplying techniques. In the case of RCCI engines it can give measurable effects, as in the case of work where NVO allowed to achieve heavy exhaust gas recirculation RCCI case shows up to $75 \%$ methane emission reduction is attainable at low load through combined effect of increased mixture homogenization and elevated temperature at intake valve closing [19].

When it comes to fuel supplying RCCI engines, much depends on the size of the engine, and its construction. In smaller engines, which are commonly use in land vehicles like cars and trucks - space for using more than one fuel injector in cylinder head per cylinder is limited. Basically engines like that are equipped with fuel supply installations (Fig. 4 and 5), where low reactive fuel is supplied by PFI, and only high reactive fuel can be injected directly into cylinder. That technology is commonly used in all engines capacity, the idea of fuel delivery may be slightly different, but usage of carburetor or the gaseous fuel inlet valve in bigger engines are not fundamentally different from each other and their technical construction are well known. Figure 19 shows a scheme of a gas mixer.

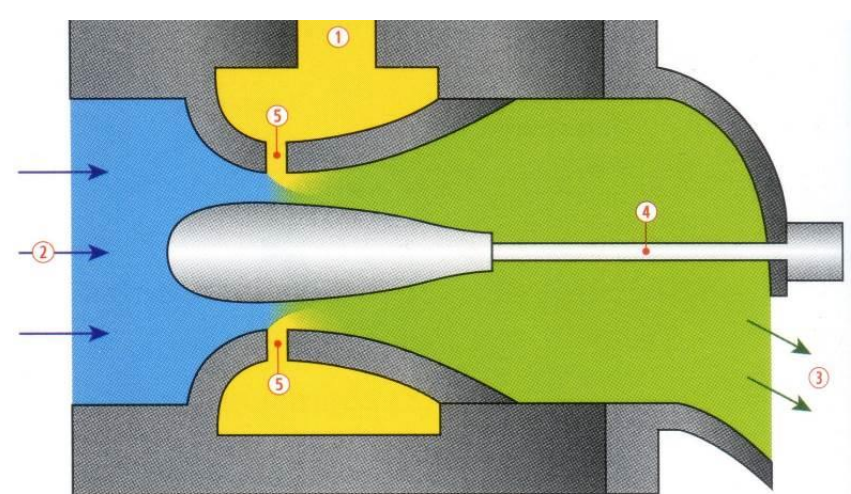

Fig. 19. A cross-sectional view of a gas mixer with an adjustable venturi insert, where 1 is the gaseous fuel supply, 2 is the air supply, 3 is the air-fuel mixture to the intake manifold of the gas- or dual-fuel engine, 4 is the adjustable venturi insert shaft connected to stepper motor, and 5 are bores for the supply of fuel-gas in the throat of the gas mixer (reproduced from [9])

The differences in the construction of such devices may differ in details but also in size, because they are used in all types of IC engines, even in the largest maritime engines. Figure 20 shows samples photos of throats intended for gas mixers mounted in the intake manifold.

When it is necessary, gas mixers working similar to carburetor are replaced by fuel injectors, localized as close to the intake valves as it is possible. It depends on the possibility of adjusting the fuel injection moment to the current demand of the engine. Those fuel injectors are not technically novelties, so their availability and knowledge of their construction is common.
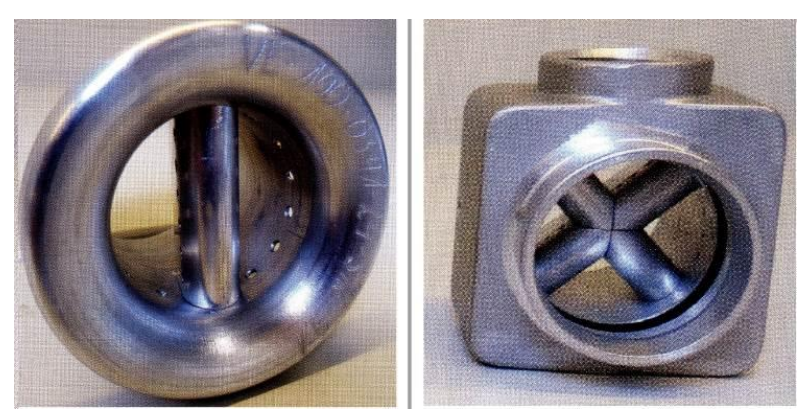

Fig. 20.The examples of throat constructions from gas mixers for different engines (reproduced from [10])

The problem in further development of RCCI engines and in general of engines operating in DF mode are direct injection systems covering injection of both used fuels.

The use of two independent injectors in the cylinder head is possible, but only in sufficiently large engines. This solution allows for direct injection of two fuels, but is technically more demanding and expensive. In maritime engines exist the system of two independent injectors of diesel fuel and liquefied natural gas (LNG) in pure form [11].

The only existing mass-produced solution in small-sized engines that allows the injection of two different fuels with one injector is the dual-fuel injector technology developed by Westport. Those injectors are already available in two generations. Injector that works in high pressure direct injection (HPDI) system includes injection of both fuels at big pressure at similar time in the same engine operation moment. The scheme of that kind of injector work is shown in the Fig. 21.

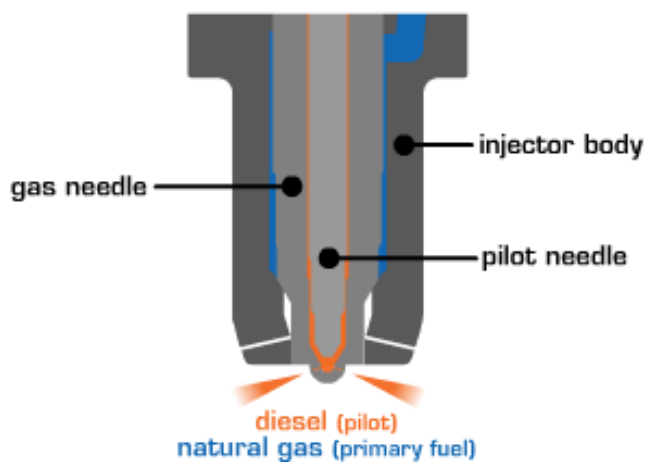

Fig. 21. Scheme of Westport company HPDI Injector Tip Assembly (reproduced from [33])

Product proposed by Westport corporation [27], and described in all relevant publications covering dual-fuel engine solutions for car and trucks [16] is only one factorymade injector available in the global market. It intended use is related to IC engines installed in heavy truck vehicles

Apart from the invention of Westport Company - and marine engines technologies with two independent injectors - DI of two fuels in small engines for passenger cars can be realized only in laboratory conditions for research purposes. In one study research team made their own handcrafted injector created for DI of CNG fuel in DF engine. Figure 19 shows the cross-section of the cylinder head with gaseous fuel injector and connection block, which is used for gaseous fuel supply for that concept DI gas injector. 


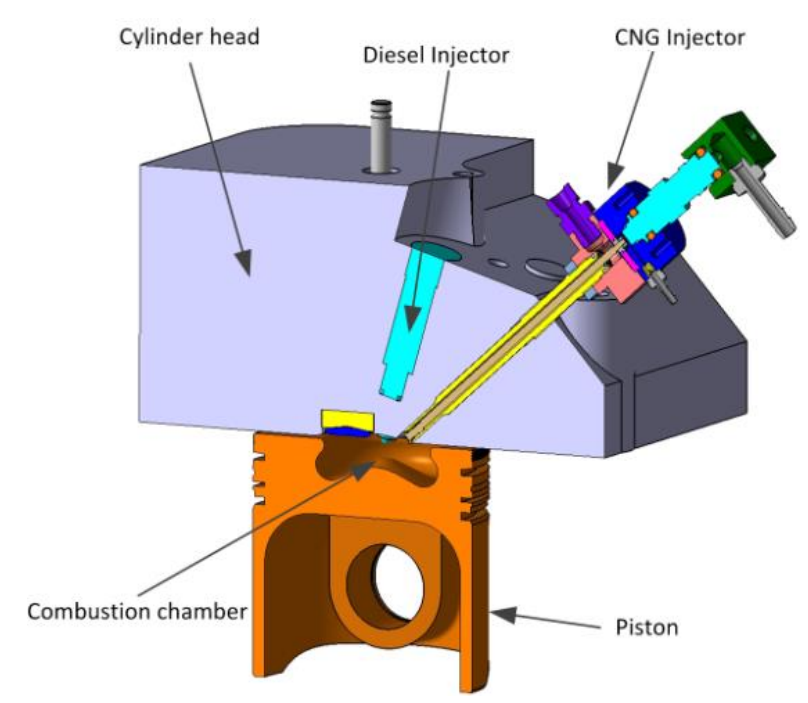

Fig. 22. The localization of the injector in CAD drawing of the cylinder head on the left and a custom gaseous-fuel injector with a parts of it on the right (reproduced from [14])

In the free market for car engines, it is hard to buy gaseous fuel direct injector, and basically impossible to buy Dual-Fuel injector - designed to inject two types of fuels simultaneously. This illustrates the early stage of development of this type of technique and its relatively low prevalence at the market. It should be borne in mind, that only DI of both fuels allows for realizing advanced fuel delivery strategies and paves the way for the development of advanced ignition techniques in IC engines, for which RCCI technique is a stop on the way to their further development.

Different group of researchers make the objective of their study to assess the potential of RCCI with direct injected low reactivity fuel in terms of thermal efficiency and methane emissions introducing gaseous fuel stratification by direct injection of it is considered to be beneficial for combustion efficiency increase [18]. Their simulation results, explanations for the observed trends are provided, and important phenomena are identified that are associated with increased low reactivity fuel stratification, which contributed to the reduction of methane emissions and an increase in $\mathrm{NO}_{\mathrm{x}}$ emissions. Authors noted the lack of a significant amount of research on the RCCI direct injection engine. Authors of [18] noted the lack of a significant amount of research on the RCCI direct injection engine: "the improvement potential of such natural gas stratification in RCCI engines is unknown" which authors of present article can also confirm to some extent, with a few exceptions, like $[21,36]$ where authors introduced term DDFS, but their research is so far focused on a limited number of engines and fuels used, so that topic is still under development for the researchers

A different approach for fuel delivery can be found in the case of two-stroke engines, where fuel can be inject into the cylinder without using the injector located in the engine's head. Figure 23 shows the injection system in two stroke marine engine, where gaseous fuel is injecting direct into the cylinder when the piston starts to move upwards, to its top position. Injected gas have got much time to create air-fuel mixture, and at the top piston position secondary high reactivity fuel is injecting, starting the combustion process. This type of RCCI engine fuel supply system is only available in marine two-stroke engines.
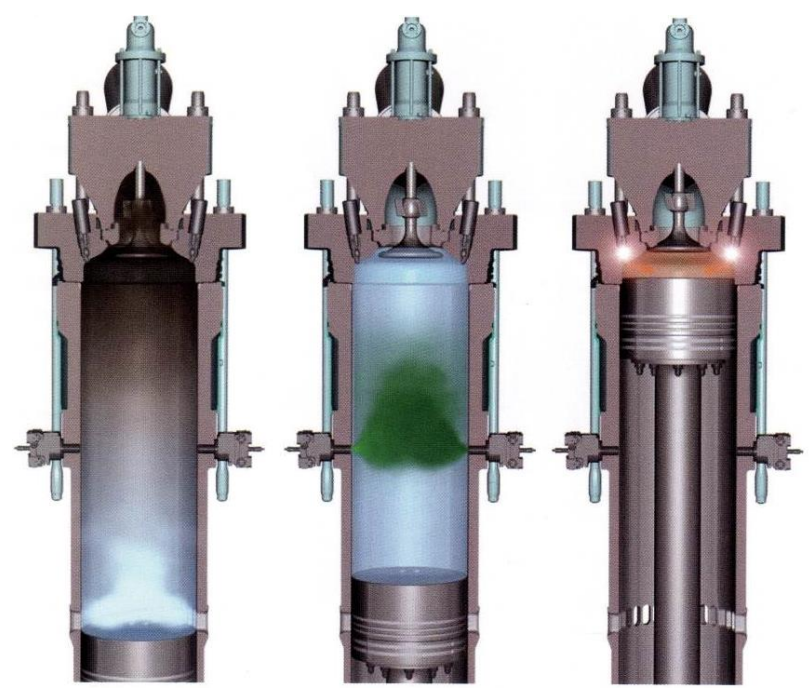

Fig. 23. Fuel injection process in two-stroke maritime engines, where the principle for the injection of low pressure gas through the cylinder liner during the upwards movement of the piston is clearly visible (reproduced from [9])

In that kind of marine engines, VVA is not a perspective technology because of two stroke engine specific construction, but researchers strongly recommend to increase knowledge and development of that technology [20]. Their experience with that technic shows that VVA makes it possible to improve combustion efficiency and thermal management (better after-treatment efficiency) and extending high load engine range. Maintaining a homogeneous mode of operation in the engine requires maintaining specific conditions. Researchers in their work create simulation concept for VVA in RCCI engine with a full load range and for two types of engine fueling: CNG-diesel and gasolinediesel.

RCCI engines are commonly used in powerplants and marine applications, so their technology is more elaborate than in small engines. Researchers also found such potential applications for these engines, and their work show the variety of research that should be carried out on engines of this type, laying the foundations for their further work based on the stratification of low reactivity fuel and VVA [17]. The development of DF engines can be traced on the basis of gaseous engines in Wärtsilä company is shown in the Fig. 24.

It is clearly visible increase in the share of engines based on dual-fuel technology. Not all of those engines listed in that figure can work in dual-fuel mode - because a few of them was only gaseous fuel - but each of them was another important step in the development of RCCI engines.

However, development issues of small-size RCCI engines also includes external equipment, such as the engine control unit, which are currently available from only one manufacturer [3]. The difference between RCCI engine development in those different engine sizes are clearly visible and still require much more research work, especially for smaller combustion engines 


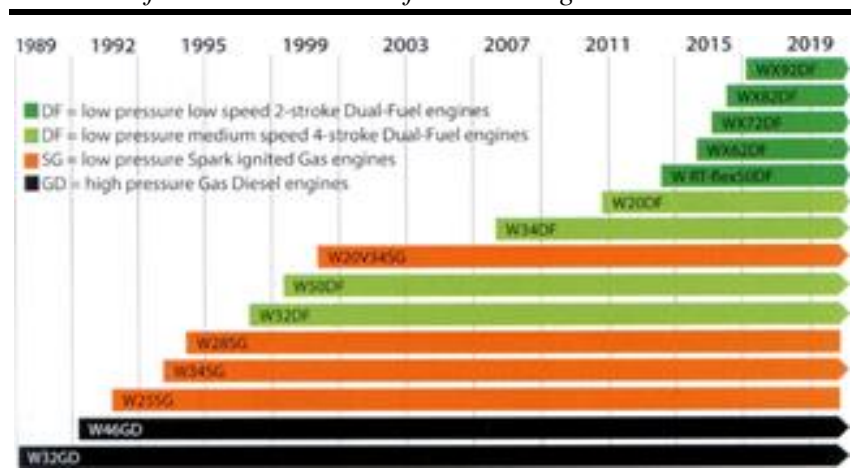

Fig. 24. Example of gaseous fuel engines development in Wärtsilä company between 1989 to $2015+$ is the extensive portfolio of Wärtsilä gas- and dual-fuel engines for both two-stroke and four-stroke engine (reproduced from [9])

The last but extremely important technical challenge facing the researchers is to control the entire engine systems so it can work in the RCCI mode throughout the entire range of engine performance. No solution in this matter can be considered ready if it has not been tested in a working engine, which has so far been addressed by a small number of researchers and the publication [28]. There are not many such publications at that moment, but they are the most desirable type of publications summarizing the achievements in the field of all techniques used in RCCI engines. The correct electronic control of the engine operation will be necessary for the RCCI mode to be effectively used in the future of IC engines.

\section{Conclusions}

The intensive development of injection technology for both independent fuels is still needed in the context of current solutions of RCCI engines. Low reactivity fuel stratification could be the main point for future development of these engines, unfortunately there are few publications regarding DDFS topic.

There are also problems with the correct air-fuel swirl ratio and the injection angle of highly reactive fuel. It is necessary to adapt the injection shape by adapting it to the new geometry of the combustion chamber. There is some research on the subject, but much remains to be done in this subject (most studies are only computer simulations or theoretical considerations).

The combustion chamber geometry is not yet optimized for all engines where there is a need for the DF RCCI operating mode.

The most important challenge with low reactive fuel injection is the need to create a homogeneous mixture under all engine operating conditions.

In the case of highly reactive fuel injectors, the new challenge is to spray the fuel over the entire space of the combustion chamber. The RCCI combustion chamber geometry may be substantially the entire space above the piston in the cylinder space. Injection angles and injector efficiency differ significantly from that of a classic diesel injector. Basic design assumptions should be changed.

It is worth mentioning that in the future the engine industry will have to make an effort to put these types of engines into production. All the innovative technical solutions described here have only a conceptual character or were made in a single made test engine unit. The problems of mass production of new constructions are still ahead of us.

New technical solutions, especially those that are only computer simulations, definitely require further research and tests covering the use of various types of fuels, materials and test conditions.

Researchers are also faced with the challenge of combining all the technical solutions mentioned in the article in one engine and controlling its operation in a way that enables continuous operation in the RCCI mode. This challenge may be the most demanding, but its implementation requires even more detailed research into the technical solutions themselves. Especially when we are talking about small motors that are not used in industry.

\section{Acknowledgements}

This work was financed by Military University of Technology under research project UGB 880/2021.

\section{Nomenclature}

CI compression ignition

CNG compressed natural gas

DDFS direct dual fuel stratification

DI direct injection

GDI gasoline direct injection

GDCI gasoline direct-injection compression ignition

GM general motors

IC internal combustion

HCCI homogeneous charge compression ignition

HPDI high pressure direct injection

LNG liquefied natural gas

LPG liquefied petroleum gas

LTC low temperature combustion
NVO negative valve overlap

PCCI Premixed Chargé Controlled Ignition

PFI port fuel injection

PPC Partially premixed combustion

PPCI partially premixed compression ignition

RCCI reactivity-controlled compression ignition

SACI spark assist compression ignition

SCR selective catalytic reduction

SI spark ignition

SPCCIspark plug controlled compression ignition

SPI single point injection

TDC top dead center

VVA variable valve actuation 


\section{Bibliography}

[1] CURAN, S., HANSON, R.M., WAGNER, R.M. et al. Efficiency and emissions mapping of RCCI in a light-duty diesel engine. SAE Technical Paper 2013-01-0289.

https://doi.org/10.4271/2016-01-2309

[2] DAHODWALA, M., JOSHI, S., KOEHLER, E. et al. Investigation of Diesel-CNG RCCI combustion at multiple engine operating conditions. SAE Technical Paper 2020-01-0801. 2020. https://doi.org/10.4271/2020-01-0801

[3] DEEN SHIPPING (Mr G. Deen), ARENARED (Mr P. Nooijen), DOLDERMAN (Mr J. Been). Breakthrough LNG deployment in Inland Waterway Transport, Activity 2.3 Evaluation report pilot test MTS Argonon, LNG Binnenvaart \& Deen Shipping, Rotterdam 2020.

[4] DELVESCOVO, D.A. The effects of fuel stratification and heat release rate shaping in Reactivity Controlled Compression Ignition (RCCI) combustion. PhD Thesis. University of Wisconsin, Madison 2016.

[5] FIRMANSYAH, A., RASHID, A.A., MORGAN, R.H. et al. Reactivity Controlled Compression Ignition (RCCI) of gasoline-CNG mixtures, improvement trends for internal combustion engines. IntechOpen Book Series. 2017. https://doi.org/10.5772/intechopen.72880

[6] HANSON, R.M., CURRAN, S.J., WAGNER, R.M. et al. Piston bowl optimization for RCCI combustion in a lightduty multi-cylinder engine. SAE Technical Paper 2012-010380. 2012. https://doi.org/10.4271/2012-01-0380

[7] KALSI, S.S., SUBRAMANIAN, K.A. Experimental investigations of effects of hydrogen blended CNG on performance, combustion and emissions characteristics of a biodiesel fuelled reactivity-controlled compression ignition engine (RCCI). International Journal of Hydrogen Energy. 2017, 42(7), 4548-4560.

https://doi.org/10.1016/j.ijhydene.2016.12.147

[8] KOKJOHN, S.L., HANSON, R.M., SPLITTER, D.A. et al. Fuel reactivity-controlled compression ignition (RCCI): A pathway to controlled high-efficiency clean combustion. International Journal of Engine Research. 2011, 12(3). https://doi.org/10.1177/1468087411401548

[9] KUIKEN, K. Gas- and dual-fuel engines for ship propulsion, power plants and cogeneration. Book I: Principles, Target Global Energy Training. PJ Onnen. The Netherlands 2016.

[10] KUIKEN, K. Gas- and dual-fuel engines for ship propulsion, power plants and cogeneration. Book II: Engine systems and environment, Target Global Energy Training. PJ Onnen. The Netherlands 2016.

[11] KUIKEN, K. Gas- and dual-fuel engines for ship propulsion, power plants and cogeneration. Book III: Operation and maintenance, Target Global Energy Training. PJ Onnen. The Netherlands 2016.

[12] KULKARNI, A.M., STRICKER, K., BLUM, A. et al. PCCI control authority of a modern diesel engine outfitted with flexible intake valve actuation. Journal of Dynamic Systems Measurement and Control. 2010, 132(5), 051009. https://doi.org/10.1115/1.4002106

[13] LUONG, M.B., SANKARAN, R., YU, G.H. et al. On the effect of injection timing on the ignition of lean PRF/air/EGR mixtures under direct dual fuel stratification conditions. Combustion and Flame. 2017, 183, 309-321. https://doi.org/10.1016/j.combustflame.2017.05.023

[14] MAJCZAK, A., BARAŃSKI, G., SOCHACZEWSKI, R. et al. CNG injector research for dual fuel engine. Advances in Science and Technology - Research Journal. 2017, 11(1), 212-219. https://doi.org/10.12913/22998624/68458

[15] MEISAM, A.G. History of Gasoline Direct Compression Ignition (GDCI) engine - a review. IJRET: International
Journal of Research in Engineering and Technology. 2014, 3(1), 335-342.

https://doi.org/10.15623/IJRET.2014.0301058

[16] MELAIKA, M., HERBILlON, G., DAHLANDER, P. Spark ignition engine performance, standard emissions and particulates using GDI, PFI-CNG and DI-CNG systems. Fuel. 2021, 293, 120454. https://doi.org/10.1016/j.fuel.2021.120454

[17] MIKULSKI, M., RAMESH, S., BEKDEMIR, C. Reactivity Controlled Compression Ignition for clean and efficient ship propulsion. Energy. 2019, 182, 1173-1192. https://doi.org/10.1016/j.energy.2019.06.091

[18] MIKULSKI, M., BEKDEMIR, C. Understanding the role of low reactivity fuel stratification in a dual fuel RCCI engine a simulation study. Applied Energy. 2017, 191, 689-708. https://doi.org/10.1016/j.apenergy.2017.01.080

[19] MIKULSKI, M., BALAKRISHNAN, P., HUNICZ, J. Natural Gas-Diesel Reactivity Controlled Compression Ignition with negative valve overlap and in-cylinder fuel reforming. Applied Energy. 2019, 254, 113638.

https://doi.org/10.1016/j.apenergy.2019.113638

[20] MIKULSKI, M., BALAKRISHNAN, P., DOOSJE, E. et al. Variable valve actuation strategies for better efficiency load range and thermal management in an RCCI engine. SAE Technical Paper 2018-01-0254. 2018. https://doi.org/10.4271/2018-01-0254

[21] MINH, B.L., RAMANAN, S., GWANG, H.Y. et al. A DNS study of the effects of injection timing on the ignition of PRF/air mixture under direct dual fuel stratification (DDFS) conditions. The 8th European Combustion Meeting. Dubrovnik 2017.

[22] PACHIANNAN, T., ZHONG, W., RAJKUMAR, S. et al. A literature review of fuel effects on performance and emission characteristics of low-temperature combustion strategies. Applied Energy. 2019, 251, 113380. https://doi.org/10.1016/j.apenergy.2019.113380

[23] PAYKANI, A., GARCIA, A., SHAHBAKHTI, M. et al. Reactivity controlled compression ignition engine: Pathways towards commercial viability. Applied Energy. 2021, 282, 116174. https://doi.org/10.1016/j.apenergy.2020.116174

[24] PAYKANI, A., KAKAEE, A-H., RAHNAMA, P. et al. Progress and recent trends in reactivity-controlled compression ignition engines. International Journal of Engine Research. 2016, 17, 481-524.

https://doi.org/10.1177/1468087415593013

[25] PAYKANI, A., AMIRHASAN, K., POURYA, R. et al. Progress and recent trends in reactivity-controlled compression ignition engines. International Journal of Engine Research. 2015, 17(5), 481-524. https://doi.org/10.1177/1468087415593013

[26] RAO, A., MEHRA, R.K., DUAN, H. et al. Comparative study of the $\mathrm{NO}_{\mathrm{x}}$ prediction model of HCNG engine. International Journal of Hydrogen Energy. 2017, 42(34), 22066-22081. https://doi.org/10.1016/j.ijhydene.2017.07.107

[27] Westport Fuel Systems Inc. https://wfsinc.com/

[28] Real world RCCI: reactively controlled ignition goes live. The Motorship Insight For Marine Technology Professionals. 2020.

https://www.motorship.com/news101/ships-equipment/realworld-rcci-reactively-controlled-ignition-goes-live

[29] REITZ, D.R., DURAISAMY, G. Review of high efficiency and clean reactivity controlled compression ignition (RCCI) combustion in internal combustion engines. Progress in Energy and Combustion Science. 2015, 46, 12-71. https://doi.org/10.1016/j.pecs.2014.05.003 
[30] ROBERTSON, D., PRUCKA, R.A. Review of sparkassisted compression ignition (SACI) research in the context of realizing production control strategies. 14th International Conference on Engines \& Vehicles. 2019. https://doi.org/10.4271/2019-24-0027

[31] SPLITTER, D., WISSINK, M., DELVESCOVO, D. et al. RCCI engine operation towards $60 \%$ thermal efficiency. SAE Technical Paper 2013-01-0279. 2013. https://doi.org/10.4271/2013-01-0279

[32] STOREY, J.M.E., CURRAN, S.J., LEWIS, S.A. et al. Evolution and current understanding of physicochemical characterization of particulate matter from reactivity controlled compression ignition combustion on a multicylinder lightduty engine. International Journal of Engine Research. 2016, 18(5-6), 505-519.

https://doi.org/10.1177/1468087416661637
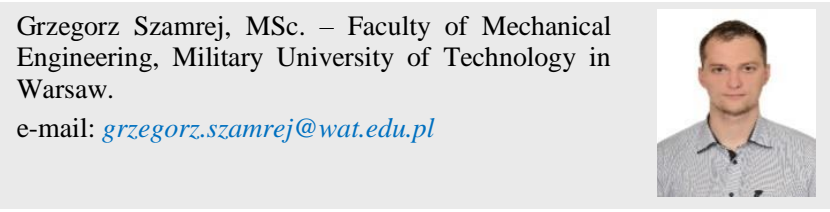

Mirosław Karczewski, DEng. - Faculty of Mechanical Engineering, Military University of Technology in Warsaw.

e-mail: miroslaw.karczewski@wat.edu.pl
[33] WEICHAI, Westport secures Chinese certification for WP12 natural gas engine powered by HPDI 2.0. Green Car Congress 2020.

[34] Westport. Natural gas vehicle technologies for light, medium, heavy and high horsepower applications, 2013.

[35] WOODYARD, D. Pounder's Marine Diesel Engines (Eighth Edition) and Gas Turbines. 2004, 641-663.

[36] YAOPENG, L., MING, J., LEILEI, X. et al. Multipleobjective optimization of methanol/diesel dual-fuel engine at low loads: a comparison of reactivity controlled compression ignition (RCCI) and direct dual fuel stratification (DDFS) strategies. Fuel. 2020, 262, 116673. https://doi.org/10.1016/j.fuel.2019.116673

[37] The ArenaRed performance.

https://www.arenared.nl/cpbc+\%7E+rcci
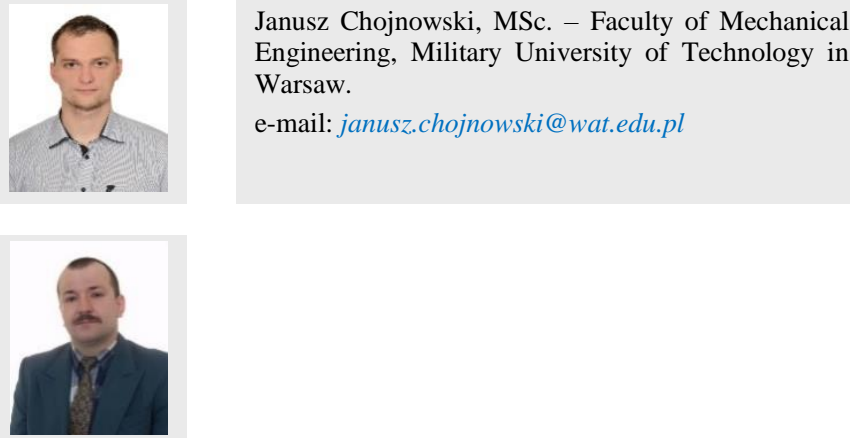